\title{
Records of sea-ice extent and air temperature at the Sea of Okhotsk from an ice core of Mount Ichinsky, Kamchatka
}

\author{
Sumito MATOBA, ${ }^{1}$ Takayuki SHIRAIWA, ${ }^{1}$ Akane TSUSHIMA, ${ }^{2}$ Hirotaka SASAKI, ${ }^{2}$ \\ Yaroslav D. MURAVYEV ${ }^{3}$ \\ ${ }^{1}$ Institute of Low Temperature Science, Hokkaido University, Sapporo 060-0819, Japan \\ E-mail: matoba@pop.lowtem.hokudai.ac.jp \\ ${ }^{2}$ Graduate School of Environmental Science, Hokkaido University, Sapporo 060-0810, Japan \\ ${ }^{3}$ Institute of Volcanology and Seismology, Russian Academy of Sciences Far East Branch, 9 Piip Boulevard, \\ Petropavlovsk-Kamchatsky 683006, Russia
}

\begin{abstract}
The Sea of Okhotsk is the southernmost area in the Northern Hemisphere where seasonal sea ice is produced every year. The formation of sea ice drives thermohaline circulation in the Sea of Okhotsk, and this circulation supports the high productivity in the region. However, recent reports have indicated that sea-ice production in the Sea of Okhotsk is decreasing, raising concern that the decreased sea ice will affect not only circulation but also biological productivity in the sea. To reconstruct climatic changes in the Sea of Okhotsk region, we analyzed an ice core obtained from Ichinskaya Sopka (Mount Ichinsky), Kamchatka. We assumed that the remarkable negative peaks of $\delta D$ in the ice core were caused by expansion of sea ice in the Sea of Okhotsk. Melt feature percentage (MFP), which indicates summer snowmelt, showed high values in the 1950-60s and the mid-1990s-2000s. The high MFP in the 1950-60s was assumed to be caused by an increase in cyclone activity reaching Kamchatka during a negative period of the Pacific Decadal Oscillation index, and that in the 1990-2000s may reflect the increase in solar irradiation during a positive period of the summer Arctic Oscillation index.
\end{abstract}

\section{INTRODUCTION}

The Sea of Okhotsk is the southernmost area in the Northern Hemisphere where seasonal sea ice is produced every year. Sea ice extends southward to $44^{\circ} \mathrm{N}$, corresponding to the latitude of southern France in Europe. The climate over the Sea of Okhotsk region is characterized by proximity to eastern Siberia, the cold pole of the Northern Hemisphere. A strong winter monsoon from eastern Siberia produces large amounts of sea ice along the northwestern coast of the Sea of Okhotsk. During the formation of sea ice, which consists of fresh water, extremely saline water (brine water) is rejected. Along the northwest coast of the Sea of Okhotsk, a large amount of brine water is produced in winter. This highdensity water settles on the bottom of the continental shelf, from which it flows out into the intermediate layer of the deep basins and extends over the intermediate layer of the North Pacific. The circulation driven by sea-ice production plays a significant role in providing the nutrients necessary for phytoplankton growth in the northwestern North Pacific (Nishioka and others, 2007).

Recent studies have reported a decreasing trend in seaice extent in the Sea of Okhotsk between 1979 and 2005 and an overall increase in surface air temperatures in the cold season, averaged over northern Eurasia upwind of the Sea of Okhotsk (Rayner and others, 2003; Nakanowatari and others, 2007). Moreover, Nakanowatari and others (2007) found that the formation of cold dense water has decreased and the temperature of intermediate layers in the Sea of Okhotsk has risen. There is concern that decreased sea-ice production may affect not only circulation but also biological productivity in the Sea of Okhotsk. Meanwhile, several other studies have suggested that the annual variations in sea-ice extent in the Sea of Okhotsk are controlled by the behavior of the Okhotsk high and/or Aleutian low (e.g. Parkinson 1990; Tachibana and others,
1996), or decadal climatic oscillations (Bond and others, 2003).

Ice cores obtained from glaciers and ice sheets are one of the most important archives of paleoclimatic and paleoatmospheric information. Variations in chemical signals in ice cores can be used as indicators of past air temperature, annual precipitation rate, source area of water vapor, and many other parameters. Ice-cores are a remarkably valuable proxy, especially in the pan-Okhotsk region, which contains limited sources of past meteorological, climatological and oceanographical data. To reconstruct centennial-scale climatic changes, we analyzed ice cores from the regions surrounding the northern North Pacific. On the North American side, we obtained ice cores from Mount Wrangell, Alaska, in 2003 and 2004 (Shiraiwa and others, 2004). On the Asian side, in Kamchatka we obtained ice cores from Mount Ushkovsky in 1998 (Shiraiwa and others, 1999) and Mount Ichinsky in 2006 (Matoba and others, 2007). In this paper, we discuss ice-core data from Mount Ichinsky obtained from an area facing the Sea of Okhotsk, in order to reconstruct climatic change in the Sea of Okhotsk and Kamchatka regions.

\section{SAMPLING AND ANALYTICAL METHODS}

Ichinskaya Sopka (Mount Ichinsky) $\left(55^{\circ} 46^{\prime} \mathrm{N}, 157^{\circ} 55^{\prime} \mathrm{E}\right.$; summit elevation $3607 \mathrm{~m}$ ) is in the central part of the Kamchatka Peninsula, Russia (Fig. 1). It is a stratovolcano and the highest mountain in the Sredinnyy Khrebet (Central Range). On its summit is a caldera measuring $3 \mathrm{~km} \times 5 \mathrm{~km}$. The caldera is covered with an ice cap $\sim 500 \mathrm{~m}$ in diameter. Mount Ichinsky has erupted several times in the Holocene. The age of the earliest volcanic deposit overlying a Late Pleistocene moraine is estimated to be about 10 000-15000 years, and the most recent eruptions occurred within the last 


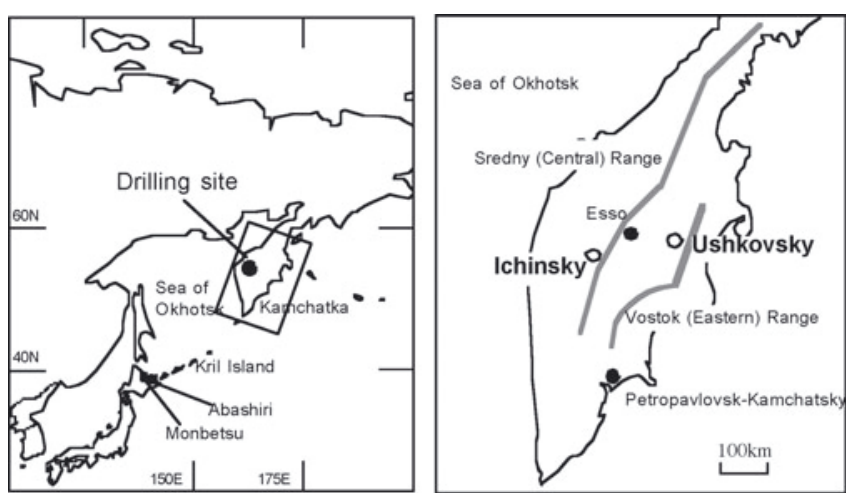

Fig. 1. Location of the study area and drilling site at Mount Ichinsky.

1800 years and at least several hundred years ago (Volynets and others, 1991). Glaciers flow from the caldera down both the steep northeast slope and the gentler southwest slope.

During the summer of 2006, we drilled down to bedrock on a glacier at the summit of Mount Ichinsky and recovered a $115 \mathrm{~m}$ long ice core (Matoba and others, 2007). We used an electromechanical ice-core drilling system developed by Geotech Co. Ltd, Nagoya, Japan. It took a total of 42.5 hours to drill down to $115 \mathrm{~m}$. An ice core $90-93 \mathrm{~mm}$ in diameter and $\sim 0.5 \mathrm{~m}$ long was consistently recovered from each drilling run. No brittle ice was found in the entire depth, despite the fact that brittle ice usually appears below depths of $100-150 \mathrm{~m}$ in mountain glaciers or small ice caps (Takahashi, 1996; Koci, 2002).

We also measured borehole temperature and constructed a profile. The temperature was $-13^{\circ} \mathrm{C}$ at $10 \mathrm{~m}$ depth and $-3.4^{\circ} \mathrm{C}$ at the bottom of the borehole. From $10 \mathrm{~m}$ to the bottom, the temperature increased linearly with depth (Matoba and others, 2007).

After drilling, we examined the stratigraphy of the ice cores and measured the diameter, length and weight of each ice-core segment to calculate its density. The pore close-off density was at $\sim 25 \mathrm{~m}$. The ice-core samples were prepared for analyses of major ions and stable isotopes as described below. The ice-core samples from the surface to $47.16 \mathrm{~m}$ depth were cut in half along their vertical axis, and cut horizontally into approximately $0.1-0.15 \mathrm{~m}$ long sections using a saw. The surface of each ice-core subsample was cut off to avoid possible contamination from drilling and processing on the outer surface of the ice core. The decontaminated subsamples were packed into polyethylene bags, melted at ambient temperature, and finally bottled in polypropylene bottles. The bottled liquid samples were transported frozen to the Institute of Low Temperature Science, Hokkaido University, (ITLS-HU) and kept frozen until the chemical and isotopic analyses were made. All equipment and bottles were pre-cleaned with ultrapure water in an ultrasonic bath. Remains of ice-core samples were transported frozen to ILTS-HU.

After ice-core drilling, we also carried out a snow-pit observation at the drilling site. The previous summer layer, indicated by the presence of a tephra layer from the strong terminal explosive-effusive eruption of Klyuchevskaya Sopka (Mount Klyuchevskoy) in 2005, appeared at 0.7 m w.e. depth. Therefore, we estimated there to be $\sim 0.7 \mathrm{~m}$ w.e. of the annual mass balance of the previous year at the drilling site.

The concentrations of major ions $\left(\mathrm{Na}^{+}, \mathrm{NH}_{4}{ }^{+}, \mathrm{K}^{+}, \mathrm{Mg}^{2+}\right.$, $\mathrm{Ca}^{2+}, \mathrm{F}^{-}, \mathrm{CH}_{3} \mathrm{SO}_{3}{ }^{-}, \mathrm{Cl}^{-}, \mathrm{NO}_{3}{ }^{-}, \mathrm{SO}_{4}{ }^{2-}$ ) were measured with

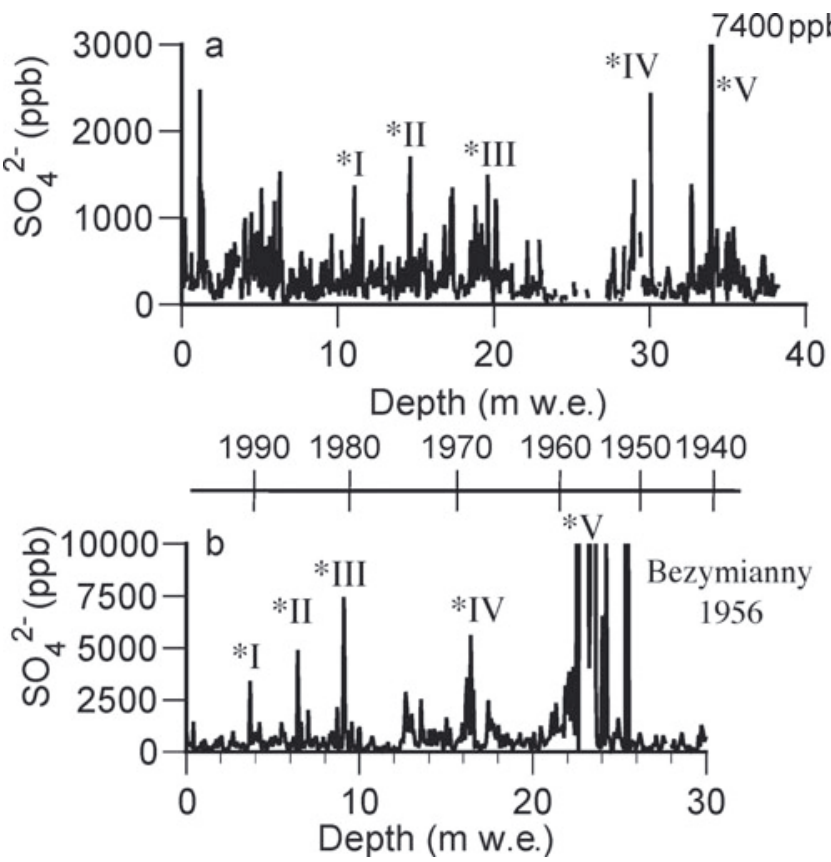

Fig. 2. Profiles of $\mathrm{SO}_{4}{ }^{2-}$ in (a) the Ichinsky ice core and (b) Ushkovsky ice core with a timescale. The timescale was estimated by annual counting of $\delta \mathrm{D}$ (Shiraiwa and Yamaguchi, 2002) and a two-dimensional thermodynamic coupled model (Salamatin and others, 2000). Roman numerals indicate inferred correlation between peaks of volcanic activity between Ichinsky and Ushkovsky.

ion chromatography (Dionex model DX500) using a $0.5 \mathrm{~mL}$ sample loop. For the cation measurements, we used a CS12 column and a $20 \mathrm{mM} \mathrm{CH} \mathrm{SO}_{3} \mathrm{H}$ eluent. For the anion measurements, an AS14 column and a $3.5 \mathrm{mM} \mathrm{Na}_{2} \mathrm{CO}_{3}$ and $1.0 \mathrm{mM} \mathrm{NaHCO}$ eluent were used. Determination limits were $<20 \mathrm{ng} \mathrm{g}^{-1}$ for $\mathrm{F}^{-}$and $<10 \mathrm{ngg}^{-1}$ for all other species. The stable-isotope composition of hydrogen $(\delta D)$ was measured with a mass spectrometer (VG Instruments model Isoprime) with a $\mathrm{Cr}$ reduction system (Eurovector model PyroOH). The precision was $<0.1 \%$. Analyses of major ions and $\delta \mathrm{D}$ were carried out at ILTS-HU.

\section{RESULTS}

\section{Ice-core chronology}

The $\delta \mathrm{D}$ profile of the Ichinsky ice core did not show clear seasonal variations, and the age of the ice core could not be determined by annual counting of $\delta \mathrm{D}$ data points. Therefore, the age of the Ichinsky ice core was estimated by comparison with ice cores obtained from the Ushkovsky ice cap $170 \mathrm{~km}$ east-northeast of Ichinsky (Fig. 1) (Shiraiwa and others, 1999, 2001). The age of the Ushkovsky ice core was determined by annual counting of $\delta \mathrm{D}$ (Shiraiwa and Yamaguchi, 2002), the presence of an index layer of volcanic material (Shiraiwa and others, 2001) and a twodimensional thermodynamic coupled model (Salamatin and others, 2000). The profiles of $\mathrm{SO}_{4}{ }^{2-}$, which originates mainly from volcanic gases, showed several significant peaks (Fig. 2). The largest peak of $\mathrm{SO}_{4}{ }^{2-}$ was at $33.90 \mathrm{~m}$ w.e. depth, which was taken to correspond to the late 1950s based on the annual mass balance of $0.7 \mathrm{mw}$.e., as described above. We determined that the peak of $\mathrm{SO}_{4}{ }^{2-}$ at $33.90 \mathrm{~m}$ w.e. in the Ichinsky ice core corresponded to the 


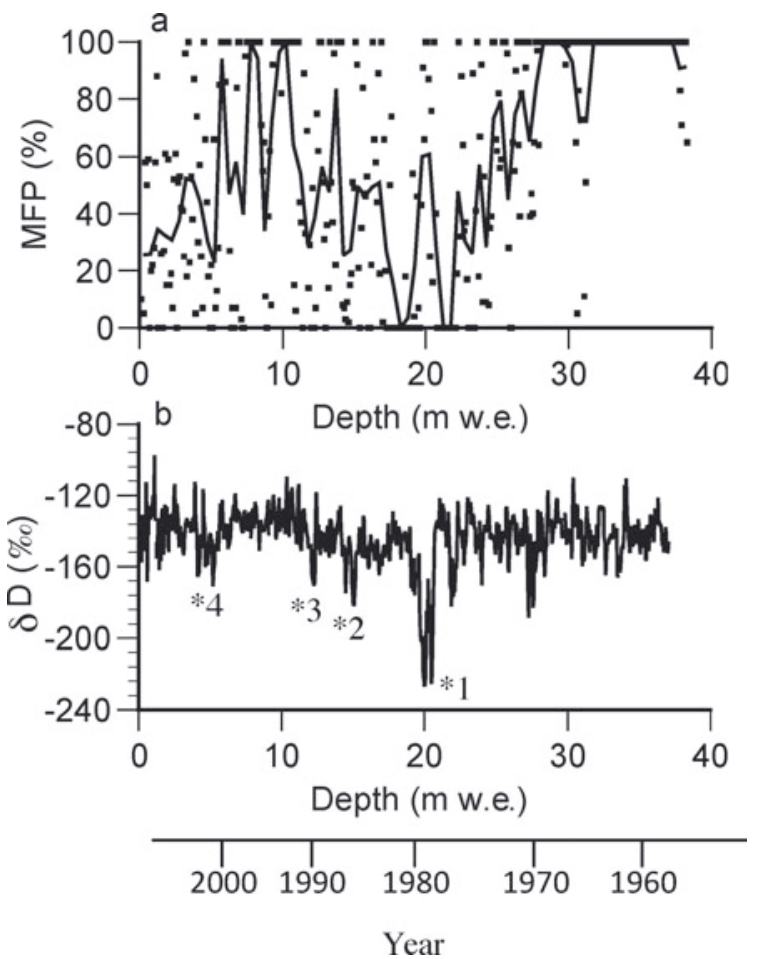

Fig. 3. Profiles of (a) the melt feature percentage (MFP) in a $0.5 \mathrm{~m}$ long section of the ice core (solid curve) and in a $0.1 \mathrm{~m}$ long section of the ice core (dots), and (b) $\delta \mathrm{D}$ with timescale. Numbers indicate peaks corresponding to intervals of high accumulated sea-ice area, marked in Figure 6.

tephra layer from the Bezymianny eruption in 1956 at $22.56 \mathrm{~m}$ w.e. depth in the Ushkovsky ice core (Murav'ev and others, 2007). We estimated the age of other signals of $\mathrm{SO}_{4}{ }^{2-}$ from the surface to $33.90 \mathrm{~m}$ w.e. depth in the Ichinsky ice core by comparison with the $\mathrm{SO}_{4}{ }^{2-}$ profile in the Ushkovsky ice core, as shown in Figure 2.

\section{Melt features}

The stratigraphy of the ice core is shown as the melt feature percentage (MFP), which is the thickness of frozen ice layers in a section of ice core $0.5 \mathrm{~m}$ w.e. long (Fig. 3). MFP from 0 to $28 \mathrm{~m}$ w.e. varied widely from 0 to $100 \%$, and that below $28 \mathrm{~m}$ w.e. was almost $100 \%$, corresponding to the 1990s and the 1960s-70s, respectively. MFP is generally used as an indicator of summer temperatures at a site where the ice layer formed only by melting occurring at the snow surface (Koerner, 1977). However, air temperatures observed at Abashiri and Monbetsu, located along the Sea of Okhotsk in Japan (meteorological data provided by the Japan Meteorological Agency, Tokyo, from their website at http:// www.jma.go.jp/jma/), did not show any high-temperature trend either in the 1990s or the 1960-70s (Fig. 4). Moreover, air temperatures at $600 \mathrm{hPa}$, corresponding to $4000 \mathrm{~m}$ in the Kamchatka region $\left(50-60^{\circ} \mathrm{N}, 155-160^{\circ} \mathrm{E}\right)$, obtained from US National Centers for Environmental Prediction (NCEP) reanalysis data, showed no warm summer period either in the 1990s or the 1960-70s (Fig. 4). Another possible cause for the increase in MFP could be an increase in solar irradiation. However, we could not find any relationship between MFP and observed meteorological data such as solar irradiation at Abashiri. Since the number of meteorological stations around the Sea of Okhotsk is limited, regional meteorological events might not show up in a reanalysis dataset. Therefore we suggest simply that the high values of MFP indicate high summer temperatures at the drilling site.

\section{Influence of melting on chemical signals}

The melting of ice may disturb the chemical signals in ice cores. Therefore the disturbance of chemical signals in ice cores by the development of meltwater must be evaluated in order to perform chemical analysis of the ice cores. The icecore layer from 0 to $28 \mathrm{mw}$.e. formed a structure of alternating layers of snow/firn and ice. The snow/firn layers did not undergo wet metamorphosis and were least
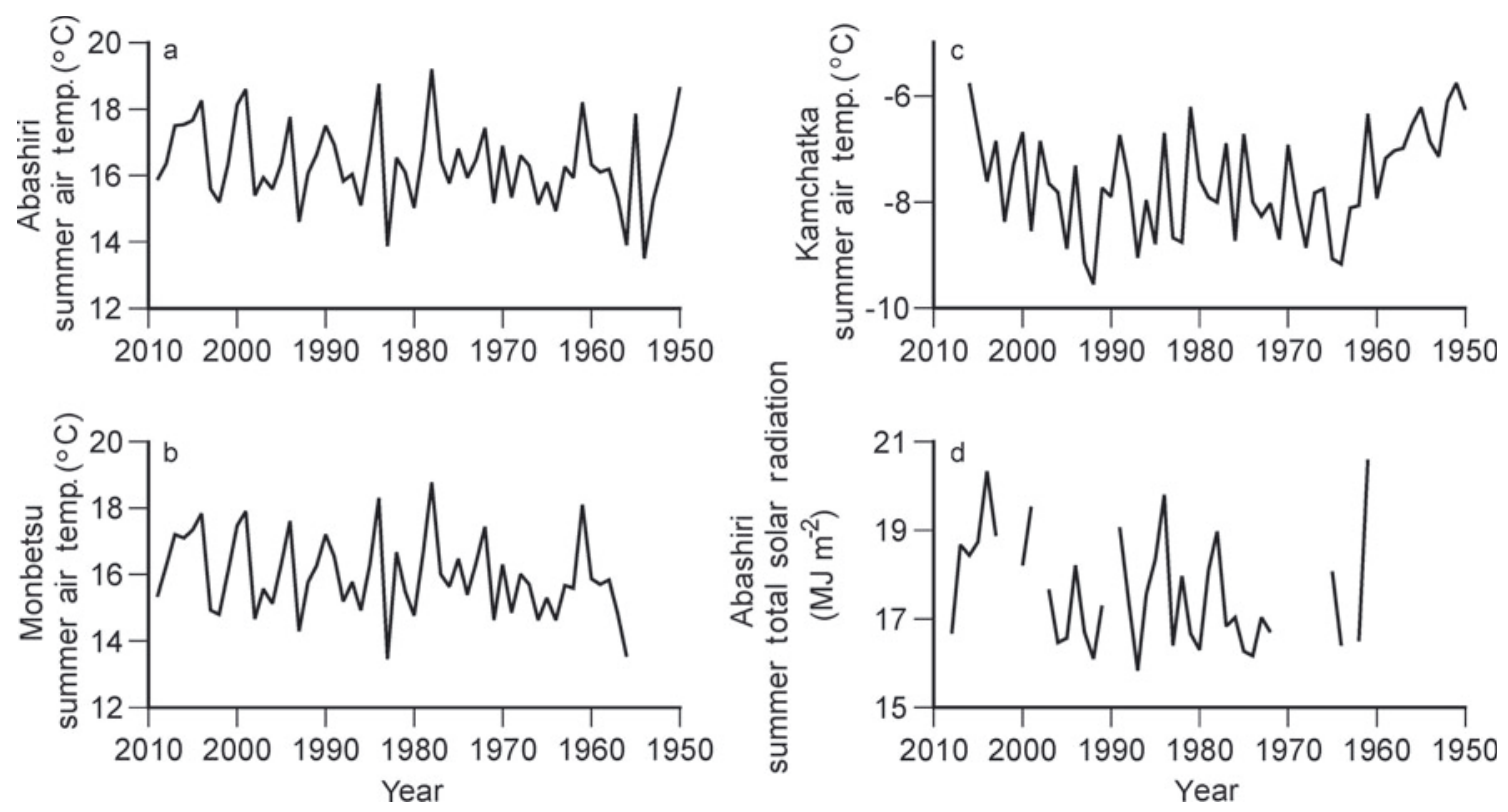

Fig. 4. Interannual variations in (a, b) summer air temperature at Abashiri (a) and Monbetsu (b); (c) average summer air temperature at $500 \mathrm{hPa}$ in the range of $50-60^{\circ} \mathrm{N}, 155-160^{\circ} \mathrm{E}$ (NCEP reanalysis data provided by the US National Oceanic and Atmospheric Administration (NOAA)/Office of Oceanic and Atmospheric Research (OAR)/Earth and Space Research Laboratory (ESRL) Physical Sciences Division (PSD) from their website at http://www.esrl.noaa.gov/psd/); and (d) summer total solar radiation observed at Abashiri. 

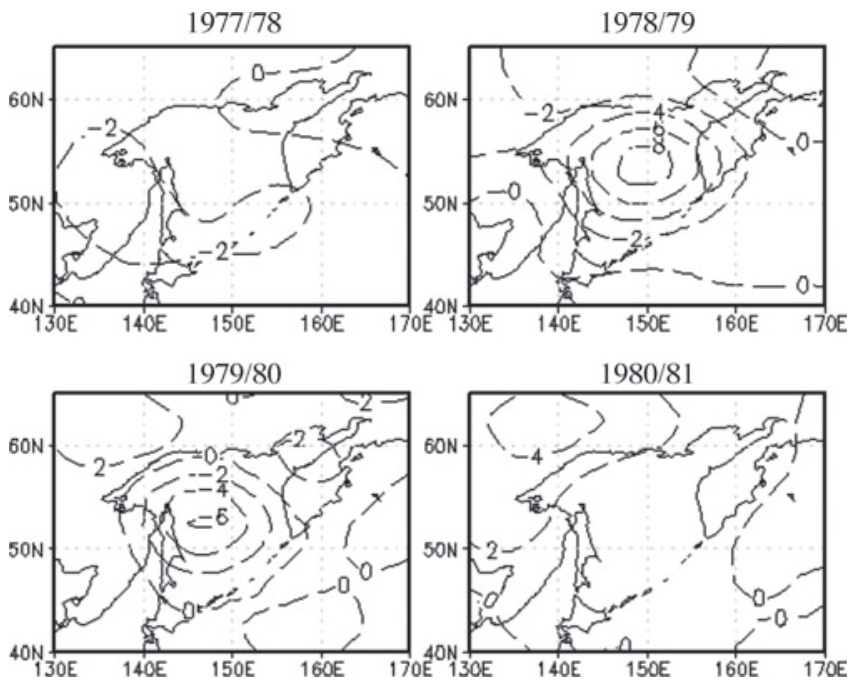

Fig. 5. Differences between DJF air temperature at $1000 \mathrm{hPa}$ from $1977 / 78$ to $1980 / 81$ and that averaged from $1950 / 51$ to $2005 / 06$ (NCEP reanalysis data provided by the NOAA/OAR/ESRL PSD from their website at http://www.esrl.noaa.gov/psd/).

influenced by meltwater. Conversely, the ice-core layer below $28 \mathrm{~m}$ w.e. consisted of ice layers. This indicates that meltwater percolated into deeper layers and over the layer from the previous summer, and that chemical profiles in the layer below $28 \mathrm{~m}$ w.e. were most influenced by meltwater. We categorized the ice-core layers into three zones according to intensity of the influence from snow meltwater using stratigraphic features as follows: (I) snow/firn layer from 0 to $28 \mathrm{~m}$ w.e., (II) clear ice layer from 0 to $28 \mathrm{~m}$ w.e., and (III) ice layer from 28 to $38 \mathrm{~m}$ w.e.

To evaluate the wash-out of chemical species from the ice core by meltwater, we compared the concentrations of chemical species in each of these zones. Table 1 shows the average concentrations of chemical species $\left(\mathrm{Na}^{+}, \mathrm{Ca}^{2+}\right.$, $\mathrm{NO}_{3}{ }^{-}, \mathrm{SO}_{4}{ }^{2-}$ ) in each zone. The concentrations of chemical species in zone I preserve the initial concentrations when snowfall occurred. Because the average concentrations of chemical species in zones II and III were comparable with those in zone I, we concluded that meltwater did not wash out chemical species from the ice layers even in zones II and III.

Table 2 shows the correlation coefficients between $\mathrm{NO}_{3}{ }^{-}$ and various chemical species $\left(\mathrm{Na}^{+}, \mathrm{Ca}^{2+}, \mathrm{SO}_{4}{ }^{2-}\right)$ in each zone. $\mathrm{NO}_{3}{ }^{-}, \mathrm{Na}^{+}, \mathrm{Ca}^{2+}$ and $\mathrm{SO}_{4}{ }^{2-}$ are emitted from different sources, i.e. combustion and biomass burning, sea salt, terrestrial dust and sea salt, and volcanic activity and sea salt, respectively. Therefore the correlation coefficients between these chemical species should not be high in the layers if wash-out of chemical species by meltwater was negligible. In fact, correlation coefficients between $\mathrm{NO}_{3}{ }^{-}$ and other species were low in zone I. However, correlation coefficients in zones II and III increased with increasing degrees of melting (zone III $>$ II $>$ I). We assumed that the enhancement of the correlation coefficient was caused by wash-out and relocation processes of chemical species by meltwater. When snowmelt occurred, meltwater washed out chemical species from the origin snow layer to deeper parts. The chemical species migrated and relocated to layers where meltwaters were refrozen; the chemical species that had washed out from different layers were thus collected and refrozen in these layers.
Table 1. Average concentrations (ppb) of chemical species in zones I-III

\begin{tabular}{lcccc}
\hline & $\mathrm{Na}^{+}$ & $\mathrm{Ca}^{2+}$ & $\mathrm{NO}_{3}{ }^{-}$ & $\mathrm{SO}_{4}{ }^{2-}$ \\
\hline Zone I $(N=205)$ & 20 & 28 & 140 & 340 \\
Zone II $(N=312)$ & 16 & 25 & 150 & 320 \\
Zone III $(N=150)$ & 18 & 36 & 150 & 330 \\
\hline
\end{tabular}

Consequently, chemical species in the ice core were washed out from initial layers and relocated in different layers, but did not run off from snow cover at the drilling site. Therefore, details obtained from chemical profiles (e.g. seasonal variations) may have been disturbed, but annual and/or decadal variations can still be examined and interpreted even in high-MFP layers.

\section{Stable-isotope ratios}

Figure 3 shows the $\delta \mathrm{D}$ profile with the corresponding timescale. Relatively high $\delta \mathrm{D}$ values appeared in the 1990s, and several negative peaks occurred during other intervals. The most remarkable negative peak, $>80 \%$ depleted, appeared in the interval corresponding to the late 1970s. Generally, stable-isotope ratios in ice cores obtained from polar regions show clear seasonal variations and can be used as an indicator of air-temperature variations. However, the $\delta \mathrm{D}$ profile in the Ichinsky ice core did not show seasonal variations, and the significant negative peaks do not seem to be directly related to variations in air temperature.

\section{DISCUSSION}

\section{Interpretation of the $\delta \mathrm{D}$ profile}

As a first step in interpreting the $\delta \mathrm{D}$ profile of the ice core, we investigated various factors that could have led to the negative excursions seen in the record corresponding to the end of the 1970s. Generally, the $\delta \mathrm{D}$ value in snow is mainly determined by the air temperature at which vapor condenses. Figure 5 shows the differences in air temperature at $1000 \mathrm{hPa}$ in winter (December-February (DJF)) in 1977/78, 1978/79, 1979/80 and 1980/81 from air temperature in winter averaged for the period 1950/51-2000/01 (NCEP reanalysis data provided by the US National Oceanic and Atmospheric Administration (NOAA)/Office of Oceanic and Atmospheric Research (OAR)/Earth and Space Research Laboratory (ESRL) Physical Sciences Division (PSD), Boulder, Colorado, from their website at http://www.esrl. noaa.gov/psd/). The results showed that a cold core of air formed over the center of the Sea of Okhotsk in 1978/79 and 1979/80. Air-temperature decreases of $8^{\circ} \mathrm{C}$ and $6^{\circ} \mathrm{C}$ were found in 1978/79 and 1979/80, respectively. In these

Table 2. Correlation coefficients between $\mathrm{NO}_{3}{ }^{-}$and chemical species $\left(\mathrm{Na}^{+}, \mathrm{Ca}^{2+}\right.$ and $\left.\mathrm{SO}_{4}{ }^{2-}\right)$ in zones I-III

\begin{tabular}{lccc}
\hline & $\mathrm{Na}^{+}$ & $\mathrm{Ca}^{2+}$ & $\mathrm{SO}_{4}{ }^{2-}$ \\
\hline Zone I $(N=205)$ & 0.20 & 0.39 & 0.63 \\
Zone II $(N=312)$ & 0.47 & 0.54 & 0.75 \\
Zone III $(N=221)$ & 0.55 & 0.68 & 0.82 \\
\hline
\end{tabular}




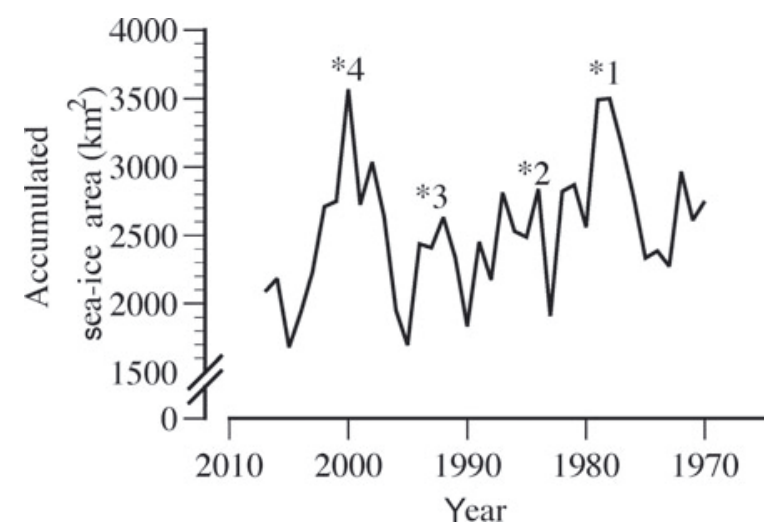

Fig. 6. Interannual variations in accumulated sea-ice area in the Sea of Okhotsk provided by the Japan Meteorological Agency. Numbers indicate peaks corresponding to negative peaks of $\delta \mathrm{D}$ as indicated in Figure 3.

seasons, cumulative sea-ice extent in the Sea of Okhotsk showed the maximum and third-maximum values on record since 1970/71 (Fig. 6). Sea ice acts as a thermal insulator during heat exchange between the atmosphere and ocean. When almost all of the Sea of Okhotsk is covered with sea ice, the heating zone migrates offshore of the Kuril Islands and the Sea of Okhotsk acts as a cooling source (Honda and others, 1996, 1999). Therefore the expansion of sea ice may have resulted in a remarkable decrease in air temperature over the Sea of Okhotsk. An air-temperature decrease of $8{ }^{\circ} \mathrm{C}$ can cause a $72 \%$ decrease in $\delta \mathrm{D}$ in precipitation, as estimated using the classic Rayleigh model with the following initial conditions: sea surface temperature (SST) of water vapor $=2^{\circ} \mathrm{C}$; water vapor equilibrated to sea surface; and initial air temperature of $-5^{\circ} \mathrm{C}$ at $1000 \mathrm{hPa}$ (Horita and Wesolowski, 1994; Boyle, 1997; Uemura, 2007). Moreover, a decrease in $\delta D$ in precipitation can also be caused by a change in the air temperature of the vapor source. When the Sea of Okhotsk is covered by sea ice, the nearest water vapor source to Mount Ichinsky might move from the west coast of Kamchatka to the coasts of the Kuril Islands. Generally, winter SSTs are $2{ }^{\circ} \mathrm{C}$ higher on the coasts of the Kuril Islands than on the west coast of Kamchatka (NOAA_ERSST_V3 data provided by the NOAA/OAR/ESRL PSD from their website at http://www.esrl.noaa.gov/psd/). Adding the condition of a $2^{\circ} \mathrm{C}$ increase in SSTs into the Rayleigh calculation described above, $\delta \mathrm{D}$ of precipitation can decrease by $83 \%$ from the initial condition, which is comparable to the decrease in $\delta \mathrm{D}$ seen in the part of the ice core corresponding to the end of the 1970s. Consequently, the significant negative peaks in $\delta \mathrm{D}$ in the Ichinsky ice core likely reflect a decrease in air temperature over the Sea of Okhotsk and an increase in SST at the vapor source.

As mentioned above, we suggest that sea ice acting as a thermal insulator during heat exchange between the atmosphere and ocean generates an air-temperature decrease at the Sea of Okhotsk. Previous studies have proposed that variations in sea-ice area in the Sea of Okhotsk are controlled by the intensity of the Aleutian low or the Siberian high (Cavalieri and Parkinson, 1987; Tachibana and others, 1996). Because air temperature in the Sea of Okhotsk depends on the area of sea ice in the sea, the development of negative peaks of $\delta \mathrm{D}$ in the Ichinsky ice core might be used as an indicator of sea-ice extent in the Sea of Okhotsk. Several peaks in the cumulative sea-ice extent in the Sea of
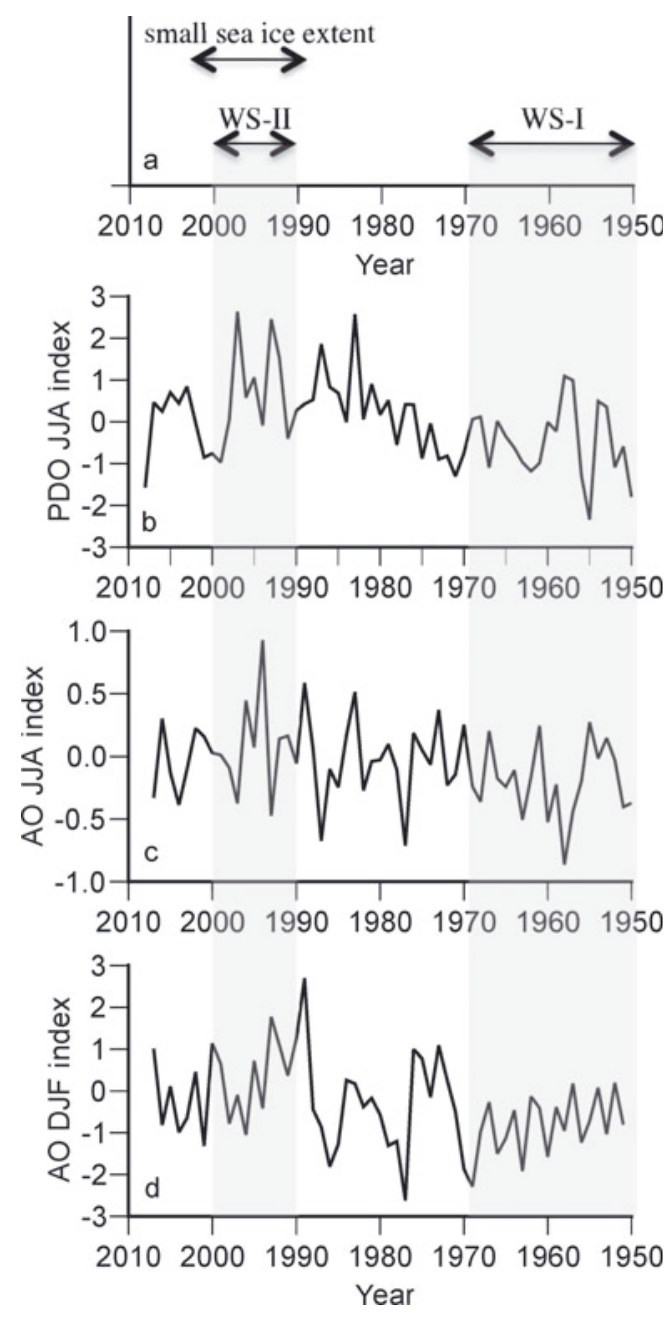

Fig. 7. Periods of small sea-ice extent and warm summers extracted from ice-core analysis (a) and temporal variations of climate indices: (b) PDO June-August (JJA) index; (c) AO JJA index; and (d) AO DJF index. Shaded areas indicate a warm-summer period.

Okhotsk seem to correspond to negative peaks in $\delta \mathrm{D}$ in the Ichinsky ice core, indicated by the arrows in Figure 5. According to the $\delta \mathrm{D}$ profile, sea-ice extent was low from 1990 to 2000 and relatively high before the 1970 s.

\section{Long-term trends in ice-core signals and climate indices}

We extracted 50 year records of climatic fluctuations from $\delta \mathrm{D}$ and MFP profiles in the Ichinsky ice core (Fig. 7). Two warm-summer periods were detected: from the beginning of the 1950s to the end of the 1960s, and from the beginning of the 1990s to the end of the 1990s (Table 3). We defined these as Warm Summer-I (WS-I) and Warm Summer-II (WSII), respectively (Fig. 7). WS-II corresponds to the period when sea-ice extent in the Sea of Okhotsk was small. To determine the factors controlling the climatic fluctuations, we compared the climatic signals obtained from the ice core with other climatic indices (Fig. 7). WS-I corresponded to a negative Pacific Decadal Oscillation (PDO) period. The PDO index is calculated by the leading principal component of monthly SST anomalies in the North Pacific north of $20^{\circ} \mathrm{N}$ (http://jisao.washington.edu/pdo/PDO.latest) (Mantua and others, 1997; Zhang and others, 1997). When the PDO index is negative, sea water in the central North Pacific Ocean tends to be warm and sea water along the west coast 
of North America tends to be cold. Several studies have reported the effect of PDO on climate fluctuations (McCabe and Fountain, 1995; Minobe, 1997), but there is no report of the direct regional effect of PDO on climate fluctuations in Kamchatka. Shiraiwa and Yamaguchi (2002) found a negative correlation between the PDO index and annual balance of Ushkovsky glacier and suggested that SSTs on the coast of Kamchatka, the frequency of traveling cyclones approaching Kamchatka and the precipitation amount all increased during the PDO negative period. Therefore we can assume that air temperatures at Kamchatka tend to be warm when the PDO index is negative, and that WS-I was associated with the phase of a negative PDO index.

Conversely, WS-Il corresponded to a positive period of the PDO index when waters in the central North Pacific Ocean tended to be cold. The origin of the WS-II period can be explained by fluctuations in the Arctic Oscillation (AO) index in summer. The $\mathrm{AO}$ is the dominant pattern of non-seasonal sea-level pressure (SLP) variations north of $20^{\circ} \mathrm{N}$ (Thompson and Wallace, 1998). In summer, a positive phase of the AO is associated with an enhanced Okhotsk high (Yamazaki, 2007). An enhanced Okhotsk high tends to induce cold summers in northern Japan and bring clear skies. We assumed that the enhanced Okhotsk high brought clear skies and caused an increase in solar irradiation at Mount Ichinsky and the Sea of Okhotsk, resulting in higher MFP.

Periods of low sea-ice extent from 1990 to 2000, as identified by the $\delta \mathrm{D}$ profile, corresponded to an interval of a positive winter $\mathrm{AO}$ index phase. When the winter $\mathrm{AO}$ index is positive, the Aleutian low and the stream of cold air from Siberia weaken. Therefore northern Japan experiences a warmer winter. The profile of the $\mathrm{AO}$ index and our interpretation of the $\delta \mathrm{D}$ data are consistent.

\section{CONCLUSION}

This study of an ice core obtained from Mount Ichinsky has revealed the following:

1. Negative peaks of $\delta \mathrm{D}$ can be used as an indicator of seaice extent in the Sea of Okhotsk.

2. Sea-ice extent estimated by the $\delta \mathrm{D}$ profile was low in 1990-2000, and low sea-ice extent continued till 2006, the year in which the ice core was recovered. The low sea-ice extent was caused by warm winters associated with a positive $\mathrm{AO}$ phase.

3. MFP showed high values in the intervals 1950-60 and 1990-2000. The high values in 1950-60 were caused by the increased frequency of traveling cyclones approaching Kamchatka in summer, associated with a negative PDO phase. The high values during 1990-2000 were related to an increase in solar irradiation in summer in the Sea of Okhotsk and Kamchatka regions, linked to a summer positive AO phase.

An ice-core indicator of sea-ice extent in the Sea of Okhotsk is a very valuable tool for reconstructing paleoclimate and paleoenvironmental variations around the Sea of Okhotsk and the northern Pacific because satellite data of sea-ice extent have only been available for this area since the 1970s. We expect that we can obtain long-term records of climatic changes in the western North Pacific regions, from the Little Ice Age to the present, from analysis of the deeper part of the Ichinsky ice core.
Table 3. Decadal variations in average MFP in the ice core

\begin{tabular}{lc}
\hline Period & MFP \\
& $\%$ \\
\hline $1950-60$ & \\
$1960-70$ & 97.5 \\
$1970-80$ & 94.8 \\
$1980-90$ & 46.9 \\
1990-2000 & 35.9 \\
2000-06 & 67.2 \\
& 39.3 \\
\hline
\end{tabular}

\section{ACKNOWLEDGEMENTS}

We express our appreciation and thanks to the Institute of Volcanology and Seismology, Russian Academy of Sciences, for support during glaciological observation in Kamchatka. We thank M. Watanabe for ion chromatography measurements. We also thank anonymous reviewers for their valuable comments. This work is a contribution to the Amur-Okhotsk Project, promoted by the Research Institute for Humanity and Nature, Japan. The field research was partly supported by a Grant-in Aid for Young Scientists (B) (No. 18740289 to the principal investigator S. Matoba) from the Ministry of Education, Culture, Sports, Science and Technology, Japan.

\section{REFERENCES}

Bond, N.A., J.E. Overland, M. Spillane and P. Stabeno. 2003. Recent shifts in the state of the North Pacific. Geophys. Res. Lett., 30(23), 2183. (10.1029/2003GL018597.)

Boyle, E.A. 1997. Cool tropical temperatures shift the global $\delta^{18} \mathrm{O}-T$ relationship: an explanation for the ice core $\delta^{18} \mathrm{O}$-borehole thermometry conflict? Geophys. Res. Lett., 24(3), 273-276.

Cavalieri, D.J. and C.L. Parkinson. 1987. On the relationship between atmospheric circulation and the fluctuations in the sea ice extents of the Bering and Okhotsk Seas. J. Geophys. Res., 92(C7), 7141-7162.

Honda, M., K. Yamazaki, Y. Tachibana and K. Takeuchi. 1996. Influence of Okhotsk sea-ice extent on atmospheric circulation. Geophys. Res. Lett., 23(24), 3595-3598.

Honda, M., K. Yamazaki, H. Nakamura and K. Takeuchi. 1999. Dynamic and thermodynamic characteristics of atmospheric response to anomalous sea-ice extent in the Sea of Okhotsk. J. Climate, 12(12), 3347-3358.

Horita, J. and D.J. Wesolowski. 1994. Liquid-vapor fractionation of oxygen and hydrogen isotopes of water from the freezing to the critical-temperature. Geochim. Cosmochim. Acta, 58(16), $3425-3437$.

Koci, B. 2002. A review of high-altitude drilling. Mem. Natl Inst. Polar Res., 56, Special Issue, 1-4.

Koerner, R.M. 1977. Devon Island ice cap: core stratigraphy and paleoclimate. Science, 196(4285), 15-18.

Mantua, N.J., S.R. Hare, Y. Zhang, J.M. Wallace and R.C. Francis. 1997. A Pacific interdecadal climate oscillation with impacts on salmon production. Bull. Am. Meteorol. Soc., 78(6), 1069-1079.

Matoba, S. and 10 others. 2007. The glaciological expedition to Mount Ichinsky, Kamchatka, Russia. Bull. Glaciol. Res., 24, 79-85.

McCabe, G.J., Jr and A.G. Fountain. 1995. Relations between atmospheric circulation and mass balance of South Cascade Glacier, Washington, U.S.A. Arct. Alp. Res., 27(3), 226-233.

Minobe, S. 1997. A 50-70 year climatic oscillation over the North Pacific and North America. Geophys. Res. Lett., 24(6), 683-686. 
Murav'ev, Ya.D., A.A. Ovsyannikov and T. Shiraiwa. 2007. Activity of the northern volcano group according to drilling data in the Ushkovsky crater glacier, Kamchatka. J. Volcanol. Seismol., 1(1), 42-52.

Nakanowatari, T., K.I. Ohshima and M. Wakatsuchi. 2007. Warming and oxygen decrease of intermediate water in the northwestern North Pacific, originating from the Sea of Okhotsk, 1955-2004. Geophys. Res. Lett., 34(4), L04602. (10.1029/ 2006GL028243.)

Nishioka, J. and 12 others. 2007. Iron supply to the western subarctic Pacific: importance of iron export from the Sea of Okhotsk. J. Geophys. Res., 112(C10), C10012. (10.1029/ 2006JC00405.)

Parkinson, C.L. 1990. The impact of the Siberian high and Aleutian low on the sea-ice cover of the Sea of Okhotsk. Ann. Glaciol., 14, 226-229.

Rayner, N.A. and 7 others. 2003. Global analyses of sea surface temperature, sea ice, and night marine air temperature since the late nineteenth century. J. Geophys. Res., 108(D14), 4407. (10.1029/2002JD002670.)

Salamatin, A.N., Y.D. Murav'yev, T. Shiraiwa and K. Matsuoka. 2000. Modelling dynamics of glaciers in volcanic craters. J. Glaciol., 46(153), 177-187.

Shiraiwa, T. and S. Yamaguchi. 2007. Reconstruction of glacier mass balances and climate changes in the Kamchatka Peninsula. J. Geogr. [Tokyo], 111(4), 476-485. [In Japanese with English summary.]

Shiraiwa, T. and 6 others. 1999. Ice core drilling at Ushkovsky ice cap, Kamchatka, Russia. Seppyo, J. Jpn. Soc. Snow Ice, 61(1), 25-40. [In Japanese with English summary.]
Shiraiwa, T. and 8 others. 2001. Characteristics of a crater glacier at Ushkovsky volcano, Kamchatka, Russia, as revealed by the physical properties of ice cores and borehole thermometry. J. Glaciol., 47(158), 423-432.

Shiraiwa, T., S. Kanamori, C.S. Benson, D. Solie and Ya.D. Murav'ev. 2004. Shallow ice-core drilling at Mount Wrangell, Alaska. Bull. Glaciol. Res., 21, 71-77.

Tachibana, Y., M. Honda and K. Takeuchi. 1996. The abrupt decrease of the sea ice over the southern part of the Sea of Okhotsk in 1989 and its relation to the recent weakening of the Aleutian Low. J. Meteorol. Soc. Jpn, 74(4), 579-584.

Takahashi, A. 1996. Development of a new shallow ice core drill. Seppyo, J. Jpn. Soc. Snow Ice, 58(1), 29-37. [In Japanese with English summary.]

Thompson, D.W.J. and J.W. Wallace. 1998. The Arctic oscillation signature in the wintertime geopotential height and temperature fields. Geophys. Res. Lett., 25(9), 1297-1300.

Uemura, R. 2007. Studies on the reconstruction of past temperature changes from stable isotopes of water: records of millennialscale climate change from polar ice cores. Quat. Res. (Japan), 46(2), 147-164. [In Japanese with English summary.]

Volynets, O.N., M.G. Patoka, I.V. Melekestsev and M.I. Zuburin. 1991. Ichinsky volcano. In Fedov, S.A. and Y.P. Masurenkov, eds. Active volcanoes of Kamchatka 1. Moscow, Nauka, 280-294.

Yamazaki, K. 2007. Arctic oscillation and climate in Japan. Low Temp. Sci., Ser. A 65, 13-19. [In Japanese with English summary.]

Zhang, Y., J.M. Wallace and D.S. Battisti. 1997. ENSO-like interdecadal variability. J. Climate, 10(5), 1004-1020. 